tions we have provided for the existence of such balanced solution.

We have demonstrated our case (existence of a non-empty set $Q_{\mathrm{s}}$ and its intersection with set $E_{\mathrm{s}}$ ) based on our own numerical example. The fact that RTJ's example produces a balanced solution under one set of parameters and an unbalanced solution under another is a secondary issue. It would be interesting to examine RTJ's conjecture for validity and proof under all possible conditions. Our response to this conjecture is that the shape and the location of set $Q_{\mathrm{s}}$ in the decision space is a function of the parameters of equations $\left(W_{i} / K_{i}\right)\left[b_{i}^{*}-f_{i}(x)\right]=D \quad \forall i \in I$. If parameters $K_{i}$ change (from the anchor values to the range values) logically one can expect some change in set $Q_{\mathrm{s}}$. How such changes occur, what general rules apply, and how sensitive is the final outcome to such changes can be the material for another paper.

Finally, we consider the discussion of the required conditions to obtain a balanced solution to be the main contribution of our paper.

\title{
References
}

1 Ogryczak W (2001). Comments on Romero C, Tamiz M and Jones DF (1998). Goal programming, compromise programming, and reference point method formulations: linkages and utility interpretations. J Opl Res Soc 52: 960-962.

2 Romero C, Tamiz M and Jones DF (2001). Reply to Professor Ogryczak. J Opl Res Soc 52: 963-964.

3 Romero C, Tamiz M and Jones DF (1998). Goal programming, compromise programming, and reference point method formulations: linkages and utility interpretations. J Opl Res Soc 49: 986-991.

Laurentian University
Huaqiao University

O Ganjavi, B Aouni

Z Wang

\section{Final reply to the comments of Professors Ganjavi et al}

Journal of the Operational Research Society (2002) 53, 931. doi:10.1057/palgrave.jors.2601371

Our original paper ${ }^{1}$ is designed to show linkages and equivalence between various multi-objective programming techniques. As part of this discussion we discuss techniques that use the Chebyshev metric and link this to the concept of perfectly balanced solutions. Our premise for the existence of perfectly equilibrated solutions is limited to the cases in which the conditions given by Ballestero and Romero hold. ${ }^{2}$ Clearly, as we mentioned in our reply, our wording was poor in places and this has led to discussions with Professors Ogryczak $^{3-6}$ and Ganjavi et al (hereafter GWA). These discussions are welcomed by us as they have given clarification in places and led to further developments and enhancements. It is obvious that some models will not have a perfectly balanced solution and in this case we think the aim should be to find the 'most balanced solution' that is also efficient. Model (7) in our original paper is our attempt to find such a solution.

We welcome any corrections and improvements upon our model. The issues raised by GWA are a good development in this area as they give the required conditions needed to obtain a balanced solution. Our example as given in the paper did indeed provide a balanced solution. Under different normalisation constants it does not, as shown by GWA. We never intended to conjecture that this model produced perfectly equilibrated solutions under all possible sets of normalisation constants.

The issue of sensitivity that GWA raise is an interesting one and worthy of further research and investigation.

\section{References}

1 Romero C, Tamiz M and Jones DF (1998). Goal programming, compromise programming, and reference point method formulations: linkages and utility interpretations. J Opl Res Soc 49: 986-991.

2 Ballestero E and Romero C (1991). A theorem connecting utility function optimisation and compromise programming. Opns Res Lett 10: 421-427.

3 Ogryczak W (2001). Comments on Romero C, Tamiz M and Jones DF (1998). Goal programming, compromise programming, and reference point method formulations: linkages and utility interpretations. J Opl Res Soc 52: 960-962.

4 Romero C, Tamiz M and Jones DF (2001). Reply to Professor Ogryczak. J Opl Res Soc 52: 962-963.

5 Ogryczak W (2001). Comments on reply by Romero et al. J Opl Res Soc 52: 963-964.

6 Tamiz M, Jones DF and Romero C (2001). Final reply to Professor Ogryczak. J Opl Res Soc 52: 964-965.

Technical University of Madrid

University of Portsmouth

C Romero

M Tamiz, DF Jones 